\title{
Laparoscopic Cystectomy of Huge Ovarian Cyst in Nulliparous Woman
}

\author{
Amarnath Thakur, Ganesh Dangal, Aruna Karki, Hema Kumari Pradhan, Ranjana Shrestha, Kabin \\ Bhattachan, Rekha Poudel, Nishma Bajracharya, Kanti Prabha Giri, Kenusha Devi Tiwari \\ Department of Obstetrics and Gynecology, Kathmandu Model Hospital, Kathmandu, Nepal.
}

Received: 1 July 2018; Accepted: 20 October 2018

DOI: 10.3126/njog.v13i3.23478

ABSTRACT

Mucinous cystadenoma arises from the totipotent surface epithelium of the ovary. Its association with Brenner tumor suggests its origin as mucinous metaplasia of the epithelioid cells. The chance of malignancy is 5-10 percent. Patients usually present with abruptly increasing abdominal mass. Cystectomy is the management of choice in these cases. It was managed by laparoscopy.

Keywords: laparoscopy, mucinous cystadenoma, nulliparous.

\section{INTRODUCTION}

Ovarian mass in nulliparous young woman need tactful approach, since management should consider her fertility preservation. Mucinous cyst adenomas comprise $15-20 \%$ of all ovarian tumors and $8 \%$ to $10 \%$ of epithelial ovarian tumors. They present as very large abdominal mass and can extend up into the abdomen. ${ }^{1}$ Benign mucinous cystadenomas comprise of $80 \%$ of mucinous ovarian tumors. ${ }^{2}$ The incidence is high between 30 and 50 years of age. Benign tumors are bilateral in 5-10\% of cases. 2 Recurrence of mucinous cystadenoma is very rare after complete excision.

\section{CASE}

A 25 years unmarried lady visited our gynecological outpatient department with complaint of increased fullness of abdomen for last two months which was not associated with abdominal pain, nausea, vomiting, bloating or waterbrash or belching. There was increase in abdominal mass abruptly within months. There was shortness of breath following slight exertion, but was not associated with orthopnea. There were no associated bladder or bowel symptoms or feature of liver dysfunction. She has history of weight loss of 5 $\mathrm{kg}$ in two months. Her menarche was at the age of 12 years with menstrual flow of four days with regular cycle of 28 to 30 days without dysmenorrhea. She did not give history of sexual contact. She had a medical history of gland tuberculosis 17 years ago for which she was treated with antitubercular treatment and was cured. Her surgical history was not significant. She

\section{CORRESPONDENCE}

Dr Amarnath Thakur

Department of Obstetrics and Gynecology

Paropakar Maternity and Women's Hospital, Thapathali,

Kathmandu, Nepal.

E-mail: jamesamar27@gmail.com

Phone: +977-9803146659 did not give history of ovarian, breast, colon or any other malignancy in family.

Her physical examination showed fair general condition with normal vital signs. There was no jaundice, edema or lymphadenopathy. Her respiratory examination showed bilateral vesicular breath sound with no added sound. Precordial examination showed normal first and second heard sound, no murmur was heard. Her abdominal examination showed soft, uniformly enlargement with cystic mass palpable upto xiphisternum, 36 weeks in size, without pulsation or peristalsis, or bowel sound. Local examination of genitalia and breast showed age appropriate development of secondary sexual characteristics.

Plain radiograph of the chest (PA view) was within normal limits. Transabdominal ultrasonography (Figure 1) showed huge abdomino-pelvic loculated cyst with multiple thin septation likely of adnexal origin.

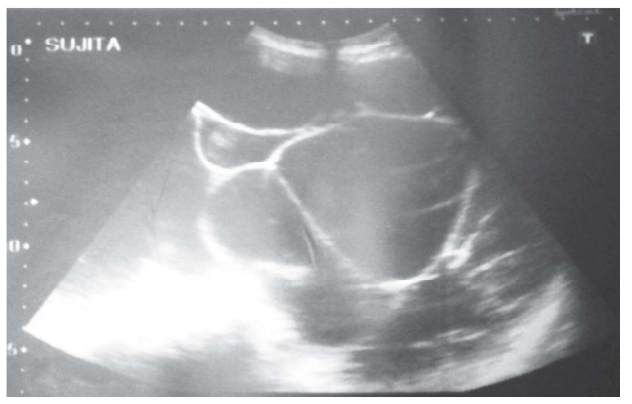

Figure 1: Ultrasonographic picture of multiloculated ovarian cyst. 
The uterus size was normal with normal endometrial thickness. Her tumour markers CA $12522.1 \mathrm{U} / \mathrm{ml}$, Serum beta HCG <2.39 IU/L, LDH 205 U/L, were all within normal limits. Abdominopelvic computerized tomography (CT) (Figure 2) showed huge intraperitoneal, thin walled, well defined, smooth, multiloculated, hypodense cystic mass measuring $34 \times 25 \times 15 \mathrm{~cm}$ (CC X TR x AR) occupying large space of the peritoneal cavity.

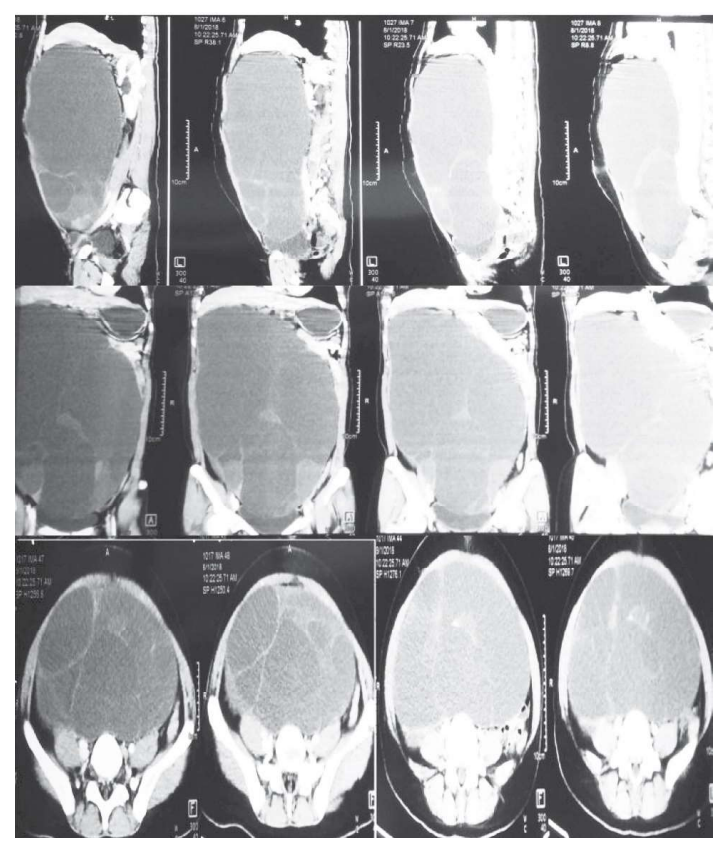

Figure 2: CT Scan view of multiloculated ovarian cyst occupying whole abdomen.

It was extending from the level of the dome of the urinary bladder, fundus of the uterus caudally and reaching upto the level of the subhepatic space on right side below the gall bladder. The mass was abutting the parietal wall anteriorly and laterally, whereas aorta, inferior venecava, ascending and descending colons posteriorly. Right ovary was not visualized separately. Grade 1 right hydronephrosis was seen.

Laparoscopic cystectomy was performed on May 2018 using $4+1$ port. The abdominal cavity was visualized with huge cyst extending upto xiphoid process. Cyst was directly punctured through umbilical port and suctioning was done (Figure-3).

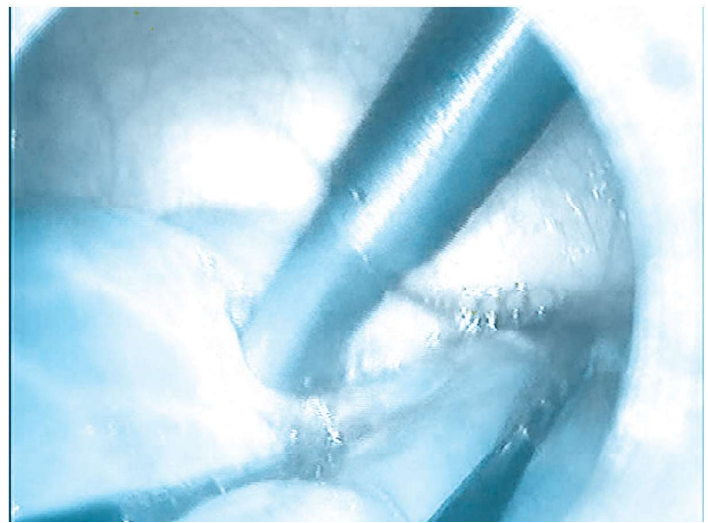

Figure 3: Laparoscopic suctioning of cystic content.

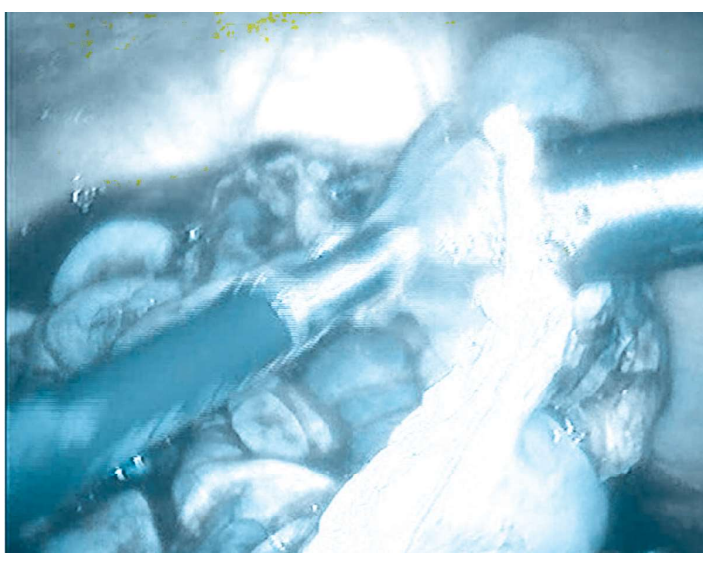

Figure 4: Laparoscopic cystectomy being done.

The cyst wall was identified (Figure 4) and removed using blunt dissection with countertraction. Small ovarian tissue was left at right ovary. There was huge multiloculated cyst arising from right ovary, containing $8.5 \mathrm{~L}$ of mucinous fluid. Right tube was enlarged whereas left tube and ovary were normal. Abdomen was washed with plenty of water after removal of cyst wall.

Abdominal drain was kept through $6 \mathrm{~mm}$ port. Estimated blood loss was $50 \mathrm{ml}$. Histopathological report came to be mucinous cystadenoma.

\section{DISCUSSION}

Ovarian cyst can be divided into either functional or neoplastic, and neoplastic tumors may be either benign or malignant. Mostly ovarian mass (80-85\%), during the reproductive period are benign. Mucinous type epithelial tumour is second most common epithelial tumor, preceded by serous type only.

Most of the ovarian cyst is managed conservatively 
with regular follow up, since most of them regress spontaneously. Surgical intervention is needed in case of complex cyst, persistent cysts, when symptomatic or when the cysts are greater than $5 \mathrm{~cm}$ in diameter. ${ }^{3}$ Nowadays laparoscopic surgery is a gold standard treatment for small to moderate size ovarian cysts.

In case of huge benign cysts, where operative procedure become difficult due to space constraint or inadequate visibility, chances of cyst rupture or spillage of cystic content in cases of malignancy, only few surgeons opt for laparoscopic management. Exact definition of huge ovarian cysts is not well defined in the literature. Some define ovarian cysts as those greater than $10 \mathrm{~cm}$ in diameter as measured by preoperative scans as huge ovarian cyst. Others define large ovarian cysts as those that are reaching above the umbilicus.

The largest mucinous cystadenoma documented tumor was $42 \times 28 \times 25 \mathrm{~cm}$ with $7.25 \mathrm{~kg}$ by Kamel ${ }^{4}$ in 2010 which was managed by laparotomy similarly Posabella et $\mathrm{al}^{5}$ reported a huge mucinous cyst adenoma of size $30 \times 34 \times 41 \mathrm{~cm}, 26.85 \mathrm{~kg}$, that again managed by laparotomy.

Previously huge ovarian cysts were managed by laprotomy followed by cystectomy. Now with recent advances in technologies and increase in laparoscopic expertise, huge ovarian cyst can be managed by laparoscopic cystectomy, but this increases the chance of cell spillage into abdominal cavity or drainage site with the potential of subsequent seeding in case of malignancy. ${ }^{6}$

Literatures till date could not give us a clear demarcation line, regarding maximal size of cyst for which laparoscopic surgery is contraindicated, but have recommended for conservative treatment in young females of reproductive age group, with cystectomy, oophorectomy, adnexectomy performed along with preservation of the uterus and contralateral adnexa.

\section{CONCLUSIONS}

Management of ovarian cysts in nulliparous women in reproductive age group depends on patient's age, size of the cyst, and its histopathological nature. Radiological evaluation and tumor marker like CA125, CEA, LDH and Serum B HCG considerably helps us to rule out malignant nature of ovarian mass. Conservative surgery such as ovarian cystectomy or salpingo-oophorectomy is adequate in mucinous tumors of ovary where recurrence is rare. In young patient with benign nature of mass without features of malignancy, where chances of recurrence is rare laparoscopic approach is simple, safe and feasible.

\section{REFERENCES}

1. HartWR. Mucinous tumors of the ovary: a review. International Journal of Gynecological Pathology. 2005;24(1):4-25

2. Berek JS, Longacre TA, Friendlander M. Ovarian fallopian tube and peritoneal cancer, In: Berek JS (Editor). Berek and Novak's Gynaecology 15th ed.India: Wolter Kluwe Health;2012.p1355-6.

3. Singla DK, Kansal R, Bansal I, Thami G, Agrawal N. Case report: laparoscopic management of a giant ovarian cyst Asian Pac J Health Sci. 2014;1:43-6

4. Kamel RM. A massive ovarian mucinous cystadenoma: a case report. Reproductive Biology and Endocrinology 2010;8(1):24
5. Posabella A, Galetti K, Engelberger S, Giovannacci L, Gyr T, Rosso R. A huge mucinous cystadenoma of ovarian: rare case report and review of the literature. Rare tumors. $2014 ; 6(2): 42-3$

6. Hunter DJ. Management of a massive ovarian cyst. Obstetrics and gynecology. 1980;56(2):254-5. 